\title{
BMJ Open Vascular function and stiffness: population epidemiology and concordance in Australian children aged 11-12 years and their parents
}

\author{
Freya K Kahn, ${ }^{\ominus 1,2}$ Melissa Wake, ${ }^{\ominus 1,3,4}$ Kate Lycett, ${ }^{\bullet 1,4,5}$ Susan Clifford, ${ }^{\oplus 1,4}$ \\ David P Burgner, ${ }^{\oplus, 4,6}$ Greta Goldsmith, ${ }^{1}$ Anneke C Grobler, ${ }^{\bullet 1,4}$ \\ Katherine Lange, ${ }^{1,4}$ Michael Cheung ${ }^{1,2,4}$
}

To cite: Kahn FK, Wake M Lycett K, et al. Vascular function and stiffness: population epidemiology and concordance in Australian children aged $11-12$ years and their parents. BMJ Open 2019:9:34-43. doi:10.1136/ bmjopen-2017-020896

- Additional material is published online only. To view please visit the journal online (http://dx.doi.org/10.1136/ bmjres-2018-020896).

Received 29 November 2017 Revised 16 February 2018 Accepted 4 April 2019
Check for updates

(C) Author(s) (or their employer(s)) 2019. Re-use permitted under CC BY-NC. No commercial re-use. See rights and permissions. Published by BMJ.

For numbered affiliations see end of article.

Correspondence to Professort Melissa Wake; melissa.wake@mcri.edu.au

\section{ABSTRACT}

Objectives To describe the epidemiology and parent-child concordance of vascular function in a population-based sample of Australian parent-child dyads at child age 11-12 years.

Design Cross-sectional study (Child Health CheckPoint), nested within a prospective cohort study, the Longitudinal Study of Australian Children (LSAC).

Setting Assessment centres in seven major Australian cities and eight regional towns or home visits, February 2015-March 2016.

Participants Of all participating CheckPoint families $(\mathrm{n}=1874), 1840$ children (49\% girls) and 1802 parents (88\% mothers) provided vascular function data. Survey weights and methods were applied to account for LSAC's complex sample design and clustering within postcodes and strata.

Outcome measures The SphygmoCor XCEL assessed vascular function, generating estimates of brachial and central systolic blood pressure and diastolic blood pressure, central pulse pressure, augmentation index and carotid-femoral pulse wave velocity. Pearson's correlation coefficients and multivariable linear regression models estimated parent-child concordance.

Results Hypertension was present in $3.9 \%$ of children and $9.0 \%$ of parents. Mean child and parent values for augmentation index were $4.5 \%$ (SD 11.6) and $21.3 \%$ (SD 12.3), respectively, and those for carotid-femoral pulse wave velocity were $4.48 \mathrm{~m} / \mathrm{s}$ (SD 0.59) and 6.85 $\mathrm{m} / \mathrm{s}$ (SD 1.14), respectively. Parent-child correlation for brachial systolic blood pressure was $0.20(95 \% \mathrm{Cl} 0.15$ to 0.24$)$, brachial diastolic blood pressure 0.21 (95\% Cl 0.16 to 0.26 ), central systolic blood pressure 0.21 (95\% Cl 0.16 to 0.25$)$, central diastolic blood pressure 0.21 (95\% Cl0.17 to 0.26$)$, central pulse pressure 0.19 (95\% Cl 0.14 to 0.24$)$, augmentation index 0.28 (95\% $\mathrm{Cl} 0.23$ to 0.32$)$ and pulse wave velocity $0.22(95 \% \mathrm{Cl}$ 0.18 to 0.27 ).

Conclusions We report Australian values for traditional and more novel vascular function markers, providing a reference for future population studies. Cross-generational concordance in multiple vascular function markers is already established by age 11-12 years, with mechanisms of heritability remaining to be explored.
Strengths and limitations of this study

- This is the largest Australian cross-sectional study to investigate vascular function concordance in parent-child dyads.

- Augmentation index, pulse wave velocity and central blood pressure were measured with gold standard non-invasive methods using applanation tonometry.

- Our adult sample comprised mainly mothers, so that estimates for almost all descriptive and concordance values were less precise for fathers.

- There is no validated transfer function for pulse wave analysis in children, so parent-child correlations for augmentation index and central blood pressures may underestimate concordance.

\section{INTRODUCTION}

Vascular dysfunction is one of the first detectable abnormalities in the pathogenesis of cardiovascular disease and is therefore often used to guide risk stratification and prevention. Traditionally, peripheral (brachial) blood pressure has been the most widely used marker of vascular function. However, non-invasive technological advances now allow vascular stiffness, an important element of vascular function, to be assessed by pulse wave analysis and pulse wave velocity. These newer measures provide additional information on cardiovascular risk and the effectiveness of drug therapy. ${ }^{1-4}$ Therefore, understanding their epidemiology across the life course (including in children) could prove essential to assist prevention efforts.

The epidemiology of blood pressure is well described and concerning. The prevalence of hypertension among US adults in 2011-2014 was $29 \%$ and has remained unchanged since the 1990 s. $^{5}$ A systematic review of West African working adults revealed an increase in prevalence of hypertension from $12.9 \%$ in the 1980 s 
to $34.4 \%$ in $2010-2014 .^{6}$ In US children, elevated blood pressure prevalence increased from $15.8 \%$ to $19.2 \%$ in boys and from $8.2 \%$ to $12.6 \%$ in girls between the 1988-1994 and 1999-2008 National Health and Nutrition Examination Surveys. ${ }^{7}$

Population-based data on measures of central blood pressure and vascular stiffness are sparser. In 2010, the Reference Values for Arterial Stiffness Collaboration pooled pulse wave velocity data from 16867 adults across eight European countries to establish reference values stratified by blood pressure and age. ${ }^{8}$ Several smaller studies have also proposed normative values for pulse wave velocity in children. ${ }^{9-11}$ However, few population studies have assessed augmentation index, a composite index influenced by reflection of pulse waves from the peripheral vasculature, arterial stiffness and contractility. These newer indices of arterial function are improving understanding of the mechanism of elevated blood pressure and have also been shown to be better predictors of adverse cardiovascular events. ${ }^{12-14}$ The Strong Heart Study showed central pulse pressure predicted cardiovascular events more strongly than brachial pulse pressure (HR 1.15 per $10 \mathrm{~mm} \mathrm{Hg}$ vs 1.10 per $10 \mathrm{~mm} \mathrm{Hg}$ ). ${ }^{15} \mathrm{In} \mathrm{a}$ meta-analysis of 17 longitudinal studies, an increase in aortic pulse wave velocity by $1 \mathrm{~m} / \mathrm{s}$ corresponded to a $15 \%$ increase in cardiovascular mortality. ${ }^{3}$

It is well established that cardiovascular disease aggregates in families, with both genes and shared environment probably contributing to this shared cardiovascular risk. ${ }^{16}$ Vascular stiffness has been shown to be moderately heritable and is increased in offspring of hypertensive parents. ${ }^{18-20}$ For example, a twin study reported heritability estimates of $60 \%, 50 \%$ and $49 \%$ for central systolic blood pressure, pulse wave velocity and augmentation index, respectively. ${ }^{21}$ However, to date, these studies have focused on heritability predominantly in adults, making it challenging to account for a lifetime of confounding factors that may be environmentally transmitted (eg, diet, smoking exposure and socioeconomic status). Further, parent-child concordance could vary by life stage. Identifying concordance in the vascular function of parents and children could allow identification of high-risk offspring early in the life course when a wide preventative window remains. For example, if concordance is high, then poor vascular function in parents could prompt investigation of their children.

The Child Health CheckPoint (CheckPoint) nested within Growing Up in Australia (also known as the Longitudinal Study of Australian Children (LSAC)) offers an unusual opportunity to report population-based data on both traditional and more novel markers of vascular function in Australian parent-child dyads measured on the same day using the same protocols. We aimed to describe vascular function in children aged 11-12years and their parents, including (1) distribution in each age group and (2) parent-child concordance.

\section{METHODS}

\section{Study design and participants}

Details of the initial study design and recruitment are outlined elsewhere. ${ }^{22}{ }^{23}$ Briefly, LSAC recruited a nationally representative B cohort of 5107 infants using a two-stage random sampling design with postcode as the primary sampling unit, and followed them up in biennial 'waves' of data collection up to 2015. The initial proportion recruited in 2004 was $57.2 \%$, of whom $73.7 \%$ $(\mathrm{n}=3764)$ were retained to LSAC wave 6 in 2014. At wave 6,3513 families consented to their contact details being shared with the CheckPoint team. From late 2014 through 2015, these families were sent an information pack via post followed by an information and recruitment phone call.

The CheckPoint was a detailed cross-sectional biophysical assessment, nested between LSAC waves 6 and 7, which took place between February 2015 and March 2016 (child age 11-12 years). A more detailed description of the CheckPoint study design is available elsewhere. ${ }^{24}{ }^{25}$

\section{Consent}

The attending parents/caregivers provided written informed consent for themselves and their children to participate in the study.

\section{Patient and public involvement}

Because LSAC is a population-based longitudinal study, no patient groups were involved in its design or conduct. To our knowledge, the public was not involved in the study design, recruitment or conduct of the LSAC study or its CheckPoint module. Parents received a summary health report for their child and themselves at or soon after the CheckPoint assessment visit. They consented to take part knowing that they would not otherwise receive individual results about themselves or their child.

\section{Procedure}

All measures of vascular function, height, weight and pubertal status were collected at a specialised 3.5-hour (seven major cities and larger regional towns) or 2.5-hour (eight smaller regional centres) CheckPoint assessment centre visit. A further 365 families who could not attend a centre received a 1.5-hour home visit (figure 1). At the visit, each child and parent separately visited the $15 \mathrm{~min}$ 'Heart Lab' station. Participants were included in the current analyses if usable data for at least one marker of vascular function were obtained (figure 1). Reasons for a lack of usable data were equipment failure, poor quality data or time constraints. Dyads were excluded from concordance analyses if the attending caregiver was not a biological parent $(n=17)$.

\section{Vascular function measures}

One of several trained technicians undertook each participant's vascular function assessment using the SphygmoCor XCEL device (AtCor Medical Pty, West Ryde, NSW, Australia). Participants were supine for several minutes prior to, and remained supine during, the measurements. 


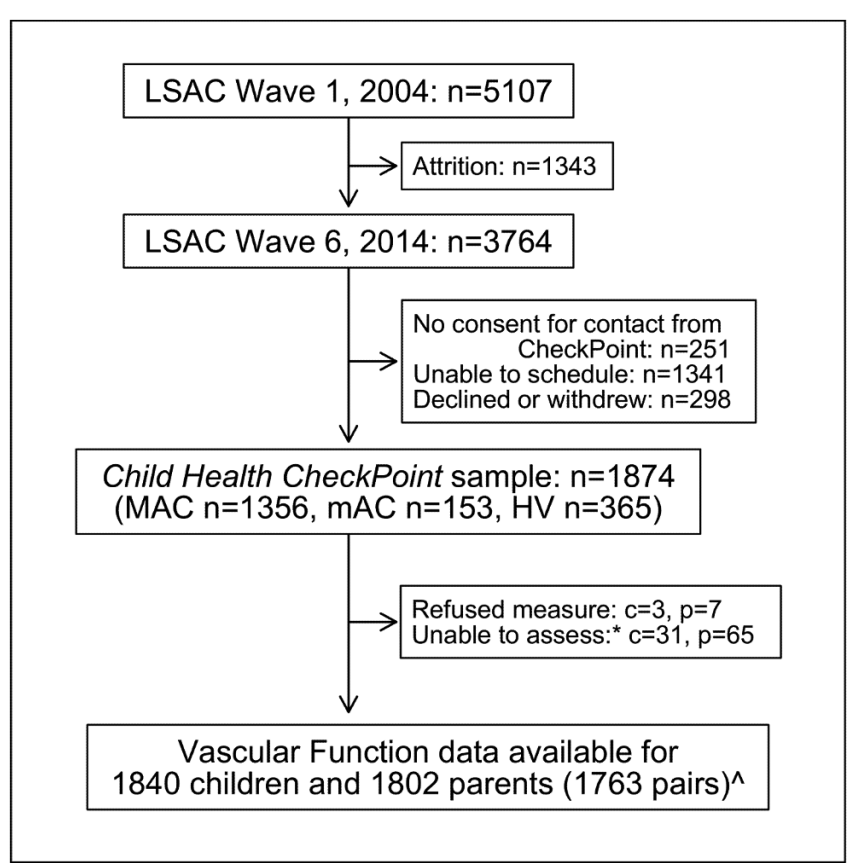

Figure 1 Participant flow through Child Health CheckPoint. *Unable to assess due to equipment failure, poor quality data or time constraints. ^Data from 17 non-biological childparent pairs excluded from concordance analyses. c, number of children; HV, home visit assessment; LSAC, Longitudinal Study of Australian Children; MAC, main assessment centre; $\mathrm{mAC}$, mini assessment centre; $n$, number of families; $p$, number of attending adults.

Vascular function variables were assessed three times (or once or twice in 860 participants for pulse wave analysis and in 497 participants for pulse wave velocity due to time constraints or other collection issue). The mean of at least two valid measurements was considered usable for that marker; markers with only one valid measurement were excluded from analyses.

Brachial systolic blood pressure and diastolic blood pressure were recorded at the brachial artery with either a standard adult cuff (for an arm circumference of $23-33 \mathrm{~cm}$ ) or a large adult cuff (for an arm circumference of $31-40 \mathrm{~cm})$. The use of 'adult' brachial cuffs in children aged 11-12years was appropriate by upper arm size for all participants. ${ }^{26}$ To define hypertension ( $\geq 95$ th percentile) and prehypertension ( $\geq 90$ th but $<95$ th) in children, we used recommendations from the 2004 National High Blood Pressure Education Program Working Group on Children and Adolescents drawn from a normative distribution of healthy children in the USA. ${ }^{27}$ For parents, we used recommendations from the Joint National Committee on Prevention, Detection, Evaluation, and Treatment of High Blood Pressure. This defines systolic hypertension as systolic blood pressure $\geq 140 \mathrm{~mm} \mathrm{Hg}$ and prehypertension $\geq 120$ and $<140 \mathrm{~mm} \mathrm{Hg}$, while diastolic hypertension is defined as diastolic blood pressure $\geq 90 \mathrm{~mm} \mathrm{Hg}$ and prehypertension $\geq 80$ and $<90 \mathrm{~mm} \mathrm{Hg}^{28}$

Several measures were estimated by a mathematical transfer function applied by the SphygmoCor software to waveforms recorded at the brachial artery for five seconds. The transfer function has been validated invasively in adults but is yet to be validated in children. ${ }^{29}$ Central systolic blood pressure and diastolic blood pressure are estimates of the maximum and minimum blood pressure at the aorta, respectively. Augmentation index is a composite measure of the magnitude of the reflected pressure wave and also the speed at which this travels back to the central aorta. The magnitude of the systolic pressure due to this wave is the augmentation index. Some studies use the 'AIx@75', which normalises augmentation index to a heart rate of 75 beats/min, but this uses a formula not validated in children. Therefore, we did not use this formula for the children (or, for comparability, the parents) in this study. Central pulse pressure, an estimate of the pulsatile component of blood pressure, is calculated as central systolic-central diastolic blood pressure.

Quality control parameters for waveforms are incorporated in the SphygmoCor software. ${ }^{1}$ At a later date, waveforms were further reviewed for quality control parameters by one of two trained analysts before entry into the CheckPoint database. Overall, 156 participants had three waveforms collected but less than three used due to poor quality waveforms. To assess inter-rater reliability, 112 individually recorded waves from a random sample of 40 participants (20 children and 20 parents) from the CheckPoint database were presented blindly to both analysts for review. The sample was stratified by an analyst, ensuring half the participants had originally been assessed by each analyst. Pulse wave quality ratings (1 'good', 2 'adequate' and 3 'poor') assigned by each analyst were compared by calculating the proportion of positive agreement between analysts. The majority of sample waveforms were assessed as being of good quality and none of poor quality. The positive agreement between analysts was high (0.99). Absolute agreement by analysts was observed for $110(98 \%)$ of the 112 waveforms assessed.

Carotid femoral pulse wave velocity is a measure of arterial stiffness. Over a $10 \mathrm{~s}$ period, the SphygmoCor system detected the time taken for the arterial waveform to propagate from the carotid (detected via a hand-held tonometer) to the femoral artery (detected simultaneously via a thigh cuff). Distance travelled by wave forms was measured with a tape measure from the carotid pulse to the suprasternal notch, from the suprasternal notch to the right femoral pulse (estimated by the crease between thigh and torso with knee bent to $90^{\circ}$ ) and from the femoral pulse to the top of the thigh cuff, and entered into the SphygmoCor software. ${ }^{1}$ Pulse wave velocity was then calculated in metres/second.

\section{Other sample characteristics including potential confounders}

Measures of vascular function are dependent on age, body mass index (BMI) and sex, which were expected to affect parent-child correlations. ${ }^{30-34}$ Sex and age were collected via parent-reported iPad questionnaires. Age was rounded to nearest week by calculating the days between the participant's date of birth and date of assessment. Height, to the 
nearest $0.1 \mathrm{~cm}$, was measured using a portable rigid stadiometer (Invicta IP0955, Leicester, UK), without shoes or socks, in light clothing, and in duplicate. A third measurement was taken if the difference of the first two measurements exceeded $0.5 \mathrm{~cm}$; final height was the mean of all measurements made. Weight, to the nearest $0.1 \mathrm{~kg}$, was measured with an InBody230 bio-electrical impedance analysis scale (Biospace Co., Seoul, South Korea) at assessment centres or with a two-limb body composition scale (Tanita BC-351, Kewdale, Western Australia) at home visits. BMI was calculated as weight $(\mathrm{kg})$ divided by height (m) squared. For children, an age-adjusted and sex-adjusted BMI z-score was calculated using the US Centers for Disease Control growth reference charts. ${ }^{35}$ Pubertal signs were self-reported using the Pubertal Development Scale $^{36}$; puberty was further categorised into prepubertal, early pubertal, midpubertal, late pubertal, and postpubertal stages. We considered any child who was in the early pubertal category or above as having started puberty.

Adjustment was also made for socioeconomic status because it is shared by parents and children and is strongly associated with higher blood pressure and higher risk of cardiovascular disease events. ${ }^{38}$ In Australia, Socio-Economic Indexes for Areas provide standardised scores for socioeconomic position by geographical area (postcode of family domicile) compiled from 2011 Australian Census data. We used the Index of Relative Socioeconomic Disadvantage (Disadvantage Index), which numerically summarises the social and economic conditions of Australian neighbourhoods (national mean of 1000 and an SD of 100, with a higher score indicating less disadvantage and a lower score indicating more disadvantage). ${ }^{39}$ Parents were also asked to self-report on their own pre-existing cardiovascular health conditions in the questionnaire (ie, history of hypertension on antihypertensive medication, history of heart disease and history of diabetes).

\section{Statistical analyses}

Data were analysed using Stata V.14.2. Vascular function measures and hypertension status were described for all children and adults (ie, regardless of relationship to child) using means and SD, and density plots. Population summary statistics and proportions were estimated by applying survey weights and survey procedures that corrected for sampling, participation and non-response biases, and took into account clustering in the sampling frame. SEs were calculated, taking into account the complex design and weights. ${ }^{40}$ More detail on the calculation of weights is provided elsewhere. ${ }^{2541}$

Concordance between all attending biological parents and children, as well as at the sex-specific level, was assessed by (1) Pearson's correlation coefficients (CCs) with 95\% CIs and (2) linear regression models with the child variable as dependent variable and the parent variable as independent variable. Linear regression models were adjusted for parent and child ages, BMI, Disadvantage
Index, and parent and child sexes in models including both sexes, based on a priori knowledge.

Concordance results were conducted with and without survey weights and survey methods. The results were similar; thus, unweighted results for concordance are presented.

Given that antihypertensive medications could mask high blood pressure and thus weaken parentchild correlations, we also repeated the analysis after excluding parents who reported use of antihypertensive medication. ${ }^{42}$

\section{RESULTS}

\section{Sample characteristics}

The recruitment and retention of participants in the CheckPoint are described in detail elsewhere..$^{25}$ Of the 1874 families that took part in CheckPoint, 1802 parents and 1840 children had at least one vascular function measure recorded at adequate quality twice or more, including 1763 biological parent-child pairs (figure 1). Characteristics of the study sample are presented in table 1 , stratified by sex.

While there were approximately equal numbers of boys and girls, most parents were mothers, with only $12 \%$ fathers. On average, children and parents were aged 12.0 (SD 0.4) and 43.7 (SD 5.7) years, respectively. The sample was from slightly less disadvantaged neighbourhood areas (mean 1009, SD 62, compared with the national mean of 1000, SD 100). Children's age-specific and sex-specific BMI z-scores were 0.36 SD above population reference values, with $6.4 \%$ of parents reporting pre-existing hypertension on antihypertensive medication.

\section{Population epidemiology of vascular function markers}

Summary statistics for child and parent vascular function measures are shown in table 2. Extended percentile values (from 5th to 95th) are provided for reference in online supplementary table 1.

All measures of vascular function were substantially higher in parents than in children, indicating a stiffer vascular tree with ageing. In children, vascular function measures were similar between sexes, with the exception of augmentation index, which was substantially higher in girls (mean 6.33\%, 95\% CI 5.50\% to $7.16 \%$ ) than boys (mean $2.75 \%$, 95\% CI $1.77 \%$ to $3.73 \%$ ). In parents, vascular function measures differed substantively by sex. Brachial and central blood pressure measures were higher in fathers than in mothers, and this pattern was also seen for pulse wave velocity (fathers' mean $7.57 \mathrm{~m} / \mathrm{s}, 95 \%$ CI 7.38 to 7.75 vs mothers' mean $6.74 \mathrm{~m} / \mathrm{s}, 95 \%$ CI 6.67 to 6.82 ). However, the opposite was observed for augmentation index, where-like the girls versus boys-mothers had higher (worse) values than fathers (mothers' mean $22.0 \%, 95 \%$ CI $21.3 \%$ to $22.8 \%$ vs fathers' mean $16.0 \%$, $95 \%$ CI $14.1 \%$ to $17.8 \%$ ). All vascular variables followed a relatively normal distribution for both children and 
Table 1 Sample characteristics; values are weighted mean (SD), except where specified as (\%)

\begin{tabular}{|c|c|c|c|}
\hline Characteristic & All & Male & Female \\
\hline \multicolumn{4}{|l|}{ Child } \\
\hline $\mathrm{n}$ & 1704-1840 & $881-935$ & 823-905 \\
\hline Age (years) & $12.0(0.4)$ & $12.0(0.4)$ & $12.0(0.4)$ \\
\hline Height (cm) & $153.8(8.0)$ & $153.3(8.2)$ & $154.3(7.7)$ \\
\hline Weight (kg) & $46.5(11.5)$ & $45.8(11.6)$ & $47.3(11.2)$ \\
\hline BMI $\left(\mathrm{kg} / \mathrm{m}^{2}\right)$ & $19.5(3.8)$ & $19.3(3.8)$ & $19.7(3.7)$ \\
\hline BMI z-score & $0.36(1.1)$ & $0.34(1.1)$ & $0.38(1.0)$ \\
\hline $\begin{array}{l}\text { Waist } \\
\text { circumference }(\mathrm{cm})\end{array}$ & $66.9(9.0)$ & $67.5(9.2)$ & $66.1(8.8)$ \\
\hline Total body fat (\%) & $22.6(9.0)$ & $21.1(9.3)$ & $24.1(8.4)$ \\
\hline $\begin{array}{l}\text { Heart rate (beats/ } \\
\text { min) }\end{array}$ & $74.4(10.0)$ & $73.1(9.8)$ & $75.6(9.9)$ \\
\hline $\begin{array}{l}\text { Disadvantage } \\
\text { Index }\end{array}$ & $1009(62)$ & $1008(62)$ & $1010(62)$ \\
\hline $\begin{array}{l}\text { Started puberty } \\
(\%)\end{array}$ & 91.5 & 88.0 & 95.4 \\
\hline *Diabetes (\%) & 0.4 & 0.3 & 0.5 \\
\hline
\end{tabular}

Parent

\begin{tabular}{|llll}
\hline $\mathrm{n}$ & $1781-1802$ & $222-225$ & $1558-1577$ \\
\hline Age (years) & $43.7(5.7)$ & $46.4(7.0)$ & $43.3(5.4)$ \\
\hline Height $(\mathrm{cm})$ & $165.7(7.9)$ & $177.7(7.3)$ & $164.1(6.4)$ \\
\hline Weight $(\mathrm{kg})$ & $77.3(18.5)$ & $91.3(17.2)$ & $75.3(17.9)$ \\
\hline BMI (kg/m²) & $28.1(6.2)$ & $28.9(4.9)$ & $28.0(6.4)$ \\
\hline $\begin{array}{l}\text { Waist } \\
\text { circumference (cm) }\end{array}$ & $87.4(15.0)$ & $98.1(13.3)$ & $85.9(14.6)$ \\
$\begin{array}{l}\text { Total body fat } \\
\text { percentage }\end{array}$ & $34.7(9.4)$ & $26.1(7.4)$ & $35.9(9.1)$ \\
$\begin{array}{l}\text { Heart rate (beats/ } \\
\text { min) }\end{array}$ & $64.7(9.9)$ & $63.2(10.3)$ & $64.9(9.8)$ \\
\hline $\begin{array}{l}\text { *Diabetes (\%) } \\
\text { *Heart condition } \\
\text { (\%) }\end{array}$ & 2.7 & 4.5 & 2.5 \\
$\begin{array}{l}\text { *Pre-existing } \\
\text { hypertension (\%) }\end{array}$ & 6.4 & 5.0 & 2.5 \\
\hline
\end{tabular}

Disadvantage Index is the Index of Relative Socioeconomic Disadvantage.

${ }^{*}$ Reported by parents.

BMI, body mass index; $n$, number of participants in the cohort with this measure.

parents. Although not the purpose of this study, the expected increments of pulse wave velocity with age was noted (see scatterplots, online supplementary figure 1).

The prevalence of hypertension and prehypertension is shown in online supplementary table 2. Hypertension (systolic and/or diastolic) was found in $3.9 \%$ of children $(4.7 \%$ of boys and $3.1 \%$ of girls) and $9 \%$ of parents ( $18.2 \%$ of fathers and $7.7 \%$ of mothers).
Parent-child concordance

Table 3 shows correlation coefficient (CC) and regression coefficient (RC) estimates for concordance of vascular function measures between biological parents and children.

Parent and child vascular function correlated positively and similarly (with overlapping CIs) across all measures, regardless of parental (table 3) or child (not shown) sex. The largest correlation for all parents and children was observed for augmentation index (CC $0.28,95 \%$ CI 0.23 to 0.32 ), with augmentation index between fathers and daughters (CC $0.40,95 \%$ CI 0.20 to 0.57 , not shown in table) the largest, considering all combinations of parent and child sex. The smallest correlation between all parents and children was for central pulse pressure (CC $0.19,95 \%$ CI 0.14 to 0.24 ). This was also the smallest correlation for mothers and children (CC 0.18, 95\% CI 0.13 to 0.23 ), while diastolic blood pressure, both brachial and central measures, showed the smallest correlations between fathers and children (CC $0.14,95 \%$ CI 0.01 to 0.28 , and CC $0.14,95 \%$ CI 0.00 to 0.27 , respectively).

All values attenuated somewhat in the adjusted linear regression models (table 3). Estimated regression coefficients for parent-child concordance ranged from 0.11 to 0.25 , and patterns were similar to the correlation results at the mother-child and father-child levels. In the sensitivity analyses excluding parents on antihypertensive medications $(n=96)$, strengths of associations were similar.

\section{DISCUSSION}

\section{Principal findings}

Our findings describe the epidemiology of vascular function, using both traditional and more novel measures, in the Australian population at two stages of the life course (11-12 years of age and midlife). For traditional measures (brachial systolic blood pressure and diastolic blood pressure) this provides important information for monitoring changes in vascular function over time and for international comparisons. For the more novel measures, these findings represent preliminary Australian normative data and key reference values, which are particularly important for understanding the physiology of vascular function in children. In addition, the moderate significant positive correlation seen for all parent-child vascular measures highlights the familial nature of vascular function, particularly for measures like augmentation index.

\section{Significance and meaning}

Age-related vascular estimates: The mean parental brachial blood pressure values we report are consistent with those of the most recent Australian Health Survey in 2011. ${ }^{43}$ Despite blood pressure being seemingly widely included in research studies, the only other quasi-national study of Australian children's blood pressure (the 1985 Australian Schools Health and Fitness Survey) is now over 30 years old. Mean systolic blood pressure in this study was around 


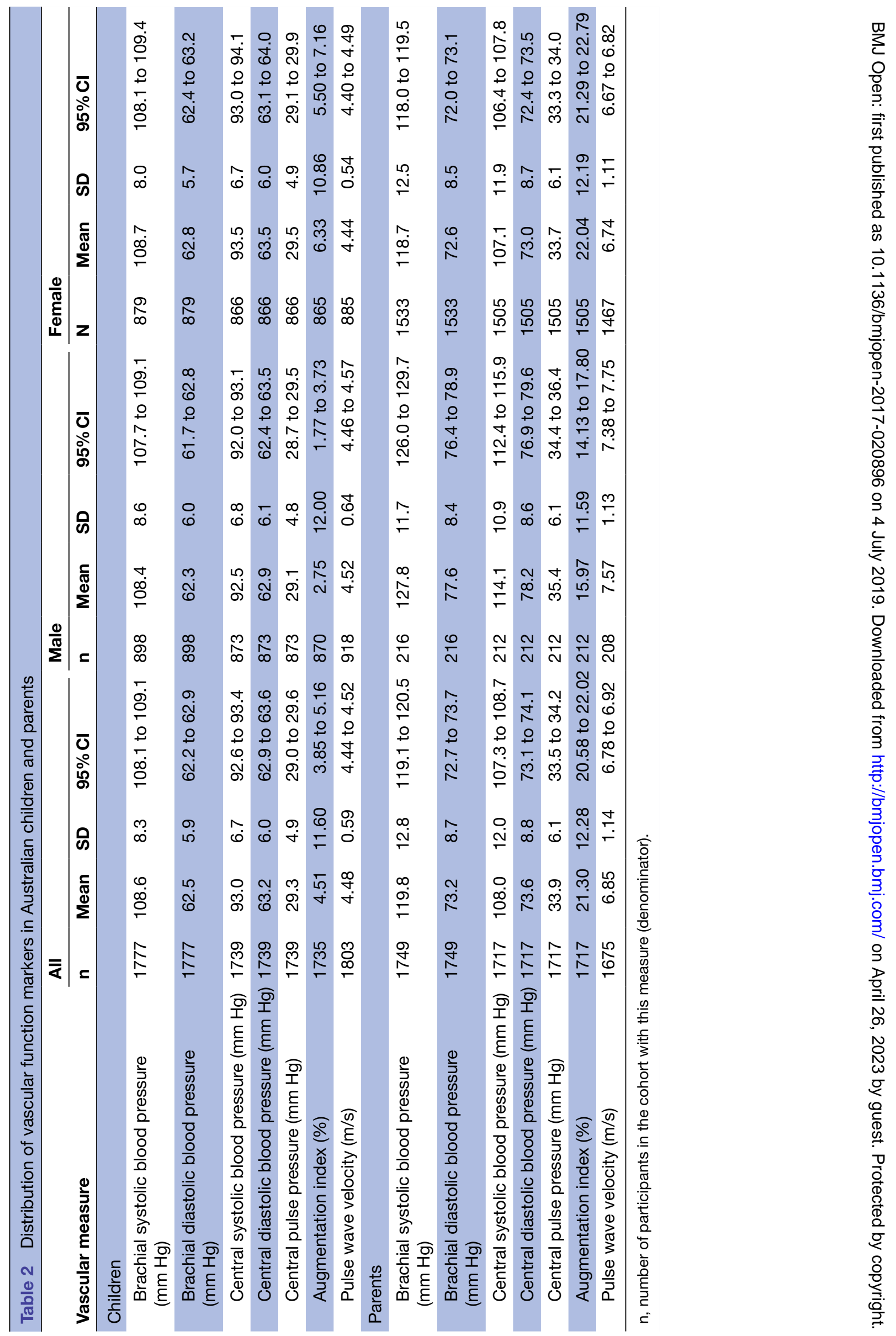


Table 3 Parent-child concordance

\begin{tabular}{|c|c|c|c|c|c|c|c|c|c|}
\hline \multirow[b]{2}{*}{ Pearson's correlation } & \multicolumn{3}{|c|}{ Parent-child } & \multicolumn{3}{|c|}{ Mother-child } & \multicolumn{3}{|c|}{ Father-child } \\
\hline & $\mathbf{n}$ & CC & $95 \% \mathrm{Cl}$ & $\mathbf{n}$ & CC & $95 \% \mathrm{Cl}$ & $\mathbf{n}$ & CC & $95 \% \mathrm{Cl}$ \\
\hline $\begin{array}{l}\text { Brachial systolic blood } \\
\text { pressure }\end{array}$ & 1666 & 0.20 & 0.15 to 0.24 & 1466 & 0.20 & 0.15 to 0.24 & 200 & 0.25 & 0.11 to 0.27 \\
\hline $\begin{array}{l}\text { Brachial diastolic blood } \\
\text { pressure }\end{array}$ & 1666 & 0.21 & 0.16 to 0.26 & 1466 & 0.22 & 0.17 to 0.27 & 200 & 0.14 & 0.01 to 0.28 \\
\hline $\begin{array}{l}\text { Central systolic blood } \\
\text { pressure }\end{array}$ & 1608 & 0.21 & 0.16 to 0.25 & 1413 & 0.21 & 0.15 to 0.25 & 195 & 0.26 & 0.12 to 0.39 \\
\hline $\begin{array}{l}\text { Central diastolic blood } \\
\text { pressure }\end{array}$ & 1608 & 0.21 & 0.17 to 0.26 & 1413 & 0.23 & 0.18 to 0.28 & 195 & 0.14 & 0.00 to 0.27 \\
\hline Central pulse pressure & 1608 & 0.19 & 0.14 to 0.24 & 1413 & 0.18 & 0.13 to 0.23 & 195 & 0.26 & 0.13 to 0.39 \\
\hline Augmentation index & 1605 & 0.28 & 0.23 to 0.32 & 1410 & 0.27 & 0.22 to 0.32 & 195 & 0.29 & 0.16 to 0.41 \\
\hline Pulse wave velocity & 1615 & 0.22 & 0.18 to 0.27 & 1415 & 0.22 & 0.17 to 0.27 & 200 & 0.29 & 0.16 to 0.41 \\
\hline $\begin{array}{l}\text { Brachial diastolic blood } \\
\text { pressure }\end{array}$ & 1655 & 0.14 & $<0.001$ & 1458 & 0.15 & $<0.001$ & 197 & 0.10 & 0.04 \\
\hline $\begin{array}{l}\text { Central systolic blood } \\
\text { pressure }\end{array}$ & 1597 & 0.10 & $<0.001$ & 1405 & 0.10 & $<0.001$ & 192 & 0.11 & 0.02 \\
\hline $\begin{array}{l}\text { Central diastolic blood } \\
\text { pressure }\end{array}$ & 1597 & 0.14 & $<0.001$ & 1405 & 0.16 & $<0.001$ & 192 & 0.10 & 0.67 \\
\hline Central pulse pressure & 1597 & 0.13 & $<0.001$ & 1405 & 0.13 & $<0.001$ & 192 & 0.13 & 0.02 \\
\hline Augmentation index & 1594 & 0.25 & $<0.001$ & 1402 & 0.26 & $<0.001$ & 192 & 0.25 & 0.002 \\
\hline Pulse wave velocity & 1606 & 0.14 & $<0.001$ & 1408 & 0.14 & $<0.001$ & 198 & 0.16 & $<0.001$ \\
\hline
\end{tabular}

Non-biological caregivers were excluded from these analyses $(n=17)$. Covariates in adjusted linear regression models include parent and child ages, BMI and Disadvantage Index, and parent and child sexes in models including both sexes.

$\mathrm{CC}$, correlation coefficient; $n$, number of biological child-parent pairs with this measure; RC, regression coefficient.

$2 \mathrm{~mm} \mathrm{Hg}$ higher in boys with a mean age of 12 years (SD $2.5)$ and around the same in girls with a mean age of 11.9 years (SD 2.4) compared with the CheckPoint's children aged 11-12years; the mean diastolic blood pressure was around 3.5 and $4 \mathrm{~mm} \mathrm{Hg}$ higher in boys and girls in the 1985 survey than in CheckPoint. ${ }^{44}$ The Lifestyles of Our Kids (LOOK) 2007 study of 573 children aged 9-10years in the Australian Capital Territory reported a slightly lower mean systolic blood pressure $(3.3 \mathrm{~mm} \mathrm{Hg}$ less $)$ but similar diastolic blood pressure $(0.3 \mathrm{~mm} \mathrm{Hg}$ less $)$. Collectively, this is in line with known age-related increments as reported by the US National High Blood Pressure Education Program Working Group on Children and Adolescents. It is reassuring that this suggests little change in blood pressure for older Australian children over the last three decades. ${ }^{27} 45$

Central aortic blood pressure norms do not exist in Australians. However, our results for parent central systolic blood pressure and diastolic blood pressure are in line with results from healthy adults with a mean age of 56-57 years (men and women, respectively), in the 1998-2001 cycle of the Framingham Offspring Study. ${ }^{46}$ The only exception was central pulse pressure, where we found higher values in both men $(6.6 \mathrm{~mm} \mathrm{Hg}$ higher $)$ and women (11.3 $\mathrm{mm} \mathrm{Hg}$ higher). ${ }^{46}$ This suggests our parent sample is at a similar or higher cardiovascular risk despite being substantially younger. Very few studies internationally have reported these values for children. A large German study in 2011-2013 that did report central blood systolic blood pressure in children employed a different type of device with its own proprietary transfer function. They reported a higher central systolic blood pressure in children aged 12 years than our study $(5.0$ and $6.3 \mathrm{~mm} \mathrm{Hg}$ higher in girls and boys, respectively), despite excluding hypertensive and obese children, ${ }^{10}$ but this may purely reflect the measurement differences.

Few studies have reported population values for augmentation index in adults and none, to our knowledge, in children. Our study therefore provides valuable preliminary normative data. A European Project on Genes in Hypertension survey of adults aged 40-49years, published in 2006, reported a lower mean augmentation index than our study (11.7\% vs $21.3 \%)$ but excluded adults with cardiovascular disease, including hypertension. ${ }^{47}$ Whereas values in Hungarian children aged 12 years were slightly higher $(5.7 \%$ and $3.0 \%$ higher in boys and girls, respectively), ${ }^{48}$ they were slightly lower in children aged 12-14years in the Canadian Study of 
Asthma Genes and Environment cohort (3.3\% and 3.7\% lower in boys and girls, respectively). ${ }^{49}$ Like us, both studies found the augmentation index to be lower in boys than in girls.

Pulse wave velocity measured across eight European countries identified a mean of $7.2 \mathrm{~m} / \mathrm{s}$ for the 40-49year age bracket, consistent with our results for parents $(6.9$ $\mathrm{m} / \mathrm{s}) .^{8}$ In healthy European children in 2006-2009, the median pulse wave velocity in children aged 12 years was similar to our findings $(4.7$ vs $4.5 \mathrm{~m} / \mathrm{s}$ in boys, 4.9 vs $4.4 \mathrm{~m} / \mathrm{s}$ in girls) ${ }^{50}$ In Australia, the smaller state-based LOOK study also reported child pulse wave velocity consistent with our data ( 4.4 vs $4.5 \mathrm{~m} / \mathrm{s}$ ). ${ }^{45}$

Parent-child concordance: In terms of brachial blood pressure concordance, semicomparable studies exist from other populations. In Norway, the HUNT study of 35050 families identified parent-child regression coefficients in brachial systolic blood pressure of 0.13 and 0.15 for fathers and mothers, respectively. These results are consistent with our findings, despite the older age of offspring in the HUNT study (mean 35.6, SD 10.6). ${ }^{42}$ Few studies have compared blood pressure in parents and offspring in childhood. In America, the Princeton Lipid Research Clinics study found no significant concurrent correlation in the mean blood pressure of offspring aged 5-19 years and their parents, perhaps due to a relatively small sample size of 95 families. ${ }^{51}$

Parent-offspring correlations of augmentation index and pulse wave velocity have not been described previously. Pulse wave velocity in adult pedigrees, with a mean age of 60 years (SD 10), was assessed in the Framingham Offspring Study, yielding a heritability of $0.4,{ }^{18}$ highly consistent with our concordance for pulse wave velocity for children/mothers (CC 0.22) and children/fathers (CG 0.29) taken together. Similarly, a study of Italian twins with a mean age of 54.6 years (SD 12.4) reported moderate heritability scores of 0.42 and 0.49 for augmentation index and pulse wave velocity, respectively. ${ }^{19}$ This suggests that cross-generational concordance in vascular stiffness is already firmly established by age 11-12 years and thence changes little through the adult lives of offspring.

The overall consistency in parent-child correlations for blood pressure (brachial and central) and vascular stiffness (augmentation index and pulse wave velocity) is unsurprising, given they are closely related measures. ${ }^{1}$ Our slightly higher concordance for augmentation index than blood pressure measures suggests either that vascular stiffness may be more heritable than blood pressure or (more plausibly) that vascular dysfunction precedes detectable elevation in blood pressure. ${ }^{52}$ Given that augmentation index and pulse wave velocity are likely to be used in future clinical practice, a known concordance between adults and offspring could help identify high-risk children early in the life course when a wide preventative window remains. However, although the correlations found in this study are substantial when considered in the context of polygenic traits, they are insufficiently precise to support cascade screening of children aged 11-12 years.

\section{Strengths and limitations}

A key strength of this study is its large, national, population-based sample, which provides a benchmark with which to develop future preventative public health initiatives, as well as normative values for Australian children aged 11-12 years and middle-aged adults. All vascular measures were collected using the current gold standard non-invasive method of applanation tonometry. ${ }^{1}$ The limited number of devices and operators and measures that were paired in time and protocol ensured highly controlled conditions of measurement and reduced many sources of potential confounding.

Limitations of this study include the validity of augmentation index as a measure of vascular stiffness or wave reflection. As a composite measure, it is limited in the ability to clearly demonstrate changes in vascular physiology. While more sensitive and technical methods of assessing wave reflection are available, these are difficult to apply to a large population study such as this. There is currently no mathematical transfer function validated by invasive aortic catheterisation in children to estimate central aortic pressure from the brachial pulse in children. Future reanalysis of the child data with a validated transfer function is likely to change the absolute values but may not have a great impact on the relative values. As such, parent-child correlations for augmentation index and central blood pressures may not change significantly, though this remains to be tested. While with parent-child dyads (rather than triads) we cannot formally estimate heritability, our firm mother-child and father-child estimates indicate that our data are closely in line with heritability estimates from more sophisticated family models. Age affects vascular function measures, so the data presented in this study apply only to children aged 11-12 years and midlife adults. ${ }^{53}$ Finally, due to baseline biases previously reported and substantial loss to follow-up, the CheckPoint sample has become less population-representative with time, as evidenced, for example, by its more advantaged sample with a narrower spread of neighbourhood disadvantage than the Australian population as a whole. This is partly mitigated by the use of survey weights and the general absence of more representative samples internationally. Finally, there were relatively few fathers, leading to wider CIs for their correlations. Although this lowers statistical power, the mother-child and fatherchild concordances in our study were similar.

\section{Conclusions and future directions}

The distributions of vascular function measures in Australian children aged 11-12 years and their parents were consistent with previous population surveys; we provide novel reference values for the newer vascular function measures. A substantial proportion of midlife parents had high blood pressure, indicating increased cardiovascular risk, which calls for increased public health measures. 
The significant moderate parent-child correlations indicate that cross-generational concordance in vascular function is already well established at age 11-12 years. Longitudinal follow-up of this cohort will reveal whether these correlations strengthen when children reach their parents' age. Family heritability (including both parents and other family members), as well as mechanistic studies, are needed to determine how arterial stiffness is transmitted.

\section{Author affiliations}

${ }^{1}$ Murdoch Children's Research Institute, Parkville, Victoria, Australia

${ }^{2}$ Department of Cardiology, The Royal Children's Hospital, Parkville, Victoria, Australia

${ }^{3}$ Department of Paediatrics and The Liggins Institute, The University of Auckland, Auckland, New Zealand

${ }^{4}$ Department of Paediatrics, The University of Melbourne, Parkville, Victoria, Australia ${ }^{5}$ School of Psychology, Deakin University, Burwood, Victoria, Australia

${ }^{6}$ Department of Paediatrics, Monash University, Melbourne, Victoria, Australia

Acknowledgements This paper uses unit record data from Growing Up in Australia, the Longitudinal Study of Australian Children (LSAC). The study is conducted in partnership between the Department of Social Services (DSS), the Australian Institute of Family Studies (AIFS) and the Australian Bureau of Statistics (ABS). Research Electronic Data Capture (REDCap) electronic data capture tools were used in this study. More information about this software can be found at www. project-redcap.org. The authors thank the LSAC and CheckPoint study participants, staff and students for their contributions.

Contributors MW, MC, KLy, SC and DPB contributed to the study design. GG, SC, FKK and KLy contributed to the acquisition of data. ACG, KLa, KLy and FKK conducted the data analysis. FKK drafted the manuscript with critical input from all authors. MW and KLy supervised FKK. MW is the principal investigator of the Child Health CheckPoint and conceived the paper. All authors read and approved the final manuscript.

Funding This work was supported by the National Health and Medical Research Council (NHMRC) of Australia (project grants 1041352 and 1109355), The Royal Children's Hospital Foundation (2014-241), the Murdoch Children's Research Institute (MCRI), The University of Melbourne, the National Heart Foundation of Australia (100660) and the Financial Markets Foundation for Children (2014-055 and 2016-310). The following authors were supported by the NHMRC: Senior Research Fellowships to MW (1046518) and DPB (1064629) and Early Career Fellowship to KLy (1091124). The following authors were supported by the National Heart Foundation of Australia: Honorary Future Leader Fellowship to DPB (100369) and Postdoctoral Fellowship to KLy (101239). MW was supported by Cure Kids New Zealand. The MCRI administered the research grants for the study and provided infrastructural support (information technology and biospecimen management) to its staff and the study, but played no role in the conduct or analysis of the trial. DSS played a role in study design; however, no other funding bodies had a role in the study design and conduct; data collection, management, analysis and interpretation; preparation, review or approval of the manuscript; and decision to submit the manuscript for publication. Research at the MCRI is supported by the Victorian Government's Operational Infrastructure Support Program.

Disclaimer The findings and views reported in this paper are those of the authors and should not be attributed to DSS, AIFS or the ABS.

Competing interests All authors have completed the International Committee of Medical Journal Editors uniform disclosure form at http://www.icmje.org/ coi_disclosure.pdf and declare financial support as described in the funding section. MW received support from Sandoz to present at a symposium outside the submitted work.

\section{Patient consent for publication Not required}

Ethics approval The CheckPoint data collection protocol was approved by The Royal Children's Hospital (Melbourne, Australia) Human Research Ethics Committee (33225D) and the Australian Institute of Family Studies Ethics Committee (14-26).

Provenance and peer review Not commissioned; externally peer reviewed.

Data sharing statement The Longitudinal Study of Australian Children datasets and technical documents are available to researchers at no cost via a licence agreement. Data access requests are co-ordinated by the National Centre for Longitudinal Data. More information is available at https://dataverse.ada.edu.au/ dataverse/ssac.

Open access This is an open access article distributed in accordance with the Creative Commons Attribution Non Commercial (CC BY-NC 4.0) license, which permits others to distribute, remix, adapt, build upon this work non-commercially, and license their derivative works on different terms, provided the original work is properly cited, appropriate credit is given, any changes made indicated, and the use is non-commercial. See: http://creativecommons.org/licenses/by-nc/4.0/.

\section{REFERENCES}

1. Laurent S, Cockcroft J, Van Bortel L, et al. Expert consensus document on arterial stiffness: methodological issues and clinical applications. Eur Heart J 2006;27:2588-605.

2. Williams B, Lacy PS, Thom SM, et al. Differential impact of blood pressure-lowering drugs on central aortic pressure and clinical outcomes: principal results of the Conduit Artery Function Evaluation (CAFE) study. Circulation 2006;113:1213-25.

3. Vlachopoulos C, Aznaouridis K, Stefanadis C. Prediction of cardiovascular events and all-cause mortality with arterial stiffness: a systematic review and meta-analysis. J Am Coll Cardiol 2010;55:1318-27.

4. Mitchell GF, Hwang SJ, Vasan RS, et al. Arterial stiffness and cardiovascular events: the Framingham Heart Study. Circulation 2010;121:505-11.

5. Yoon SS, Carroll MD, Fryar CD. Hypertension Prevalence and Control Among Adults: United States, 2011-2014. NCHS Data Brief 2015;220:1-8 https://www.cdc.gov/nchs/data/databriefs/db220.pdf.

6. Bosu WK. The prevalence, awareness, and control of hypertension among workers in West Africa: a systematic review. Glob Health Action 2015;8:26227.

7. Rosner B, Cook NR, Daniels S, et al. Childhood blood pressure trends and risk factors for high blood pressure: the NHANES experience 1988-2008. Hypertension 2013;62.

8. Reference Values for Arterial Stiffness' Collaboration. Determinants of pulse wave velocity in healthy people and in the presence of cardiovascular risk factors: 'establishing normal and reference values'. Eur Heart J 2010;31:2338-50.

9. Hidvégi EV, Illyés $M$, Benczúr $B$, et al. Reference values of aortic pulse wave velocity in a large healthy population aged between 3 and 18 years. J Hypertens 2012;30:2314-21.

10. Elmenhorst J, Hulpke-Wette M, Barta C, et al. Percentiles for central blood pressure and pulse wave velocity in children and adolescents recorded with an oscillometric device. Atherosclerosis 2015;238:9-16.

11. Thurn D, Doyon A, Sözeri B, et al. Aortic pulse wave velocity in healthy children and adolescents: reference values for the Vicorder device and modifying factors. Am J Hypertens 2015;28:1480-8.

12. Pini R, Cavallini MC, Palmieri V, et al. Central but not brachial blood pressure predicts cardiovascular events in an unselected geriatric population: the ICARe Dicomano Study. J Am Coll Cardiol 2008;51:2432-9.

13. Kaess BM, Rong J, Larson MG, et al. Aortic stiffness, blood pressure progression, and incident hypertension. JAMA 2012;308:875-81.

14. Najjar SS, Scuteri A, Shetty V, et al. Pulse wave velocity is an independent predictor of the longitudinal increase in systolic blood pressure and of incident hypertension in the Baltimore Longitudinal Study of Aging. J Am Coll Cardiol 2008;51:1377-83.

15. Roman MJ, Devereux RB, Kizer JR, et al. Central pressure more strongly relates to vascular disease and outcome than does brachial pressure: the Strong Heart Study. Hypertension 2007;50:197-203.

16. Lloyd-Jones DM, Nam BH, D'Agostino RB, et al. Parental cardiovascular disease as a risk factor for cardiovascular disease in middle-aged adults: a prospective study of parents and offspring. JAMA 2004;291:2204-11.

17. Samani NJ, Erdmann J, Hall AS, et al. Genomewide association analysis of coronary artery disease. N Engl J Med 2007;357:443-53.

18. Mitchell GF, DeStefano AL, Larson MG, et al. Heritability and a genome-wide linkage scan for arterial stiffness, wave reflection, and mean arterial pressure: the Framingham Heart Study. Circulation 2005;112:194-9.

19. Medda E, Fagnani C, Schillaci G, et al. Heritability of arterial stiffness and carotid intima-media thickness: an Italian twin study. Nutr Metab Cardiovasc Dis 2014;24:511-7.

20. Andersson C, Quiroz R, Enserro D, et al. Association of parental hypertension with arterial stiffness in nonhypertensive offspring: the Framingham Heart Study. Hypertension 2016;68:584-9. 
21. Tarnoki AD, Tarnoki DL, Stazi MA, et al. Heritability of central blood pressure and arterial stiffness: a twin study. J Hypertens 2012;30:1564-71.

22. Sanson A, Johnstone R; The LSAC Research Consortium \& FaCS LSAC Project Team. Growing Up in Australia takes its first steps. Family Matters 2004;67:46-53.

23. Edwards B. Growing Up in Australia: The Longitudinal Study of Australian Children: Entering adolescence and becoming a young adult. Family Matters 2014;95:5-14

24. Wake M, Clifford SA, York E, et al. Introducing Growing Up in Australia's Child Health CheckPoint. Family Matters 2014;95:15-23.

25. Clifford SA, Davies S, Wake M et al. Child Health CheckPoint: Cohort summary and methodology of a physical health and biospecimen module for the Longitudinal Study of Australian Children. BMJ Open 2019;9(suppl 3):3-22.

26. Stolt $M$, Sjönell $\mathrm{G}$, Aström $\mathrm{H}$, et al. Factors affecting the validity of the standard blood pressure cuff. Clin Physiol 1993;13:611-20.

27. National High Blood Pressure Education Program Working Group on High Blood Pressure in Children and Adolescents. The fourth report on the diagnosis, evaluation, and treatment of high blood pressure in children and adolescents. Pediatrics 2004;114:555-76.

28. Chobanian AV, Bakris GL, Black HR, et al. Seventh report of the joint national committee on prevention, detection, evaluation, and treatment of high blood pressure. Hypertension 2003;42:1206-52.

29. Chen CH, Nevo E, Fetics B, et al. Estimation of central aortic pressure waveform by mathematical transformation of radial tonometry pressure. Validation of generalized transfer function. Circulation 1997:95:1827-36.

30. Kelly R, Hayward C, Avolio A, et al. Noninvasive determination of age-related changes in the human arterial pulse. Circulation 1989;80:1652-9.

31. London GM, Guerin AP, Pannier BM, et al. Body height as a determinant of carotid pulse contour in humans. J Hypertens Suppl 1992;10:S93???S96-5.

32. Hayward CS, Kelly RP. Gender-related differences in the central arterial pressure waveform. J Am Coll Cardiol 1997;30:1863-71.

33. Sutton-Tyrrell K, Newman A, Simonsick EM, et al. Aortic stiffness is associated with visceral adiposity in older adults enrolled in the study of health, aging, and body composition. Hypertension 2001;38:429-33.

34. Zebekakis PE, Nawrot T, Thijs L, et al. Obesity is associated with increased arterial stiffness from adolescence until old age. $J$ Hypertens 2005;23:1839-46.

35. Kuczmarski RJ, Ogden CL, Grummer-Strawn LM, et al. CDC growth charts: United States. Adv Data 2000;314:1-27 https://www.cdc.gov/ nchs/data/series/sr_11/sr11_246.pdf.

36. Bond L, Clements J, Bertalli N, et al. A comparison of self-reported puberty using the Pubertal Development Scale and the Sexual Maturation Scale in a school-based epidemiologic survey. $J$ Adolesc 2006;29:709-20.

37. Kaczmarek M, Stawińska-Witoszyńska B, Krzyżaniak A, et al. Who is at higher risk of hypertension? Socioeconomic status differences in blood pressure among Polish adolescents: a population-based ADOPOLNOR study. Eur J Pediatr 2015;174:1461-73.

38. Senan M, Petrosyan A. The relationship between socioeconomic status and cardiovascular events. Georgian Med News 2014;227:42-7.

39. Australian Bureau of Statistics. Census of population and housing: Socio-Economic Indexes for Areas (SEIFA) 2011, 2011. Cat. no. 2033.0.55.001.

40. Heeringa SG, West BT, Berglund PA. Applied survey data analysis. Boca Raton, FL: CRC Press, 2010.

41. Ellul S, Hiscock R, Mensah FK, et al. Longitudinal Study of Australian Children's Child Health CheckPoint Technical Paper 1: Weighting and Non-Response, 2018. 10.25374/MCRI.5687593 Melbourne Murdoch Children's Research Institute.

42. Vik KL, Romundstad P, Carslake D, et al. Comparison of fatheroffspring and mother-offspring associations of cardiovascular risk factors: family linkage within the population-based HUNT Study, Norway. Int J Epidemiol 2014;43:760-71.

43. Nichols M, Peterson K, Alston L, et al. Australian heart disease statistics. Melbourne: National Heart Foundation of Australia, 2014

44. Kelly RK, Thomson R, Smith KJ, et al. Factors affecting tracking of blood pressure from childhood to adulthood: the Childhood Determinants of Adult Health Study. J Pediatr 2015;167:1422-8.

45. Sakuragi S, Abhayaratna K, Gravenmaker KJ, et al. Influence of adiposity and physical activity on arterial stiffness in healthy children: the Lifestyle Of Our Kids study. Hypertension 2009;53:611-6.

46. Mitchell GF, Parise H, Benjamin EJ, et al. Changes in arterial stiffness and wave reflection with advancing age in healthy men and women: the Framingham Heart Study. Hypertension 2004;43:1239-45.

47. Wojciechowska W, Staessen JA, Nawrot T, et al. Reference values in white Europeans for the arterial pulse wave recorded by means of the SphygmoCor device. Hypertens Res 2006;29:475-83.

48. Hidvégi EV, Illyés M, Molnár FT, et al. Influence of body height on aortic systolic pressure augmentation and wave reflection in childhood. J Hum Hypertens 2015;29:495-501.

49. Walker DJ, MacIntosh A, Kozyrskyj A, et al. The associations between cardiovascular risk factors, physical activity, and arterial stiffness in youth. J Phys Act Health 2013;10:198-204.

50. Reusz GS, Cseprekal O, Temmar M, et al. Reference values of pulse wave velocity in healthy children and teenagers. Hypertension 2010;56:217-24.

51. Morrison JA, Glueck CJ, Wang P. The child as proband for future parental cardiometabolic disease: the 26-year prospective Princeton Lipid Research Clinics Follow-up Study. J Pediatr 2012;160:590-7.

52. Asmar R, Benetos A, Topouchian J, et al. Assessment of arterial distensibility by automatic pulse wave velocity measurement. Validation and clinical application studies. Hypertension 1995;26:485-90.

53. McEniery CM, Yasmin, Hall IR, et al. Normal vascular aging: differential effects on wave reflection and aortic pulse wave velocity: the Anglo-Cardiff Collaborative Trial (ACCT). J Am Coll Cardiol 2005;46:1753-60. 